\title{
A SAÚDE PÚBLICA NAS INSTITUIÇÕES DE LONGA PERMANÊNCIA PARA
}

\section{IDOSOS}

Verônica Filter de Andrade; UFSM; veronicafilter@gmail.com

Alice do Carmo Jahn; UFSM; janhalice@gmail.com

\section{RESUMO}

Objetivo: Identificar na produção científica, estudos que descrevam acerca de como a saúde pública têm assistido as Instituições de Longa Permanência para Idosos. Método: Foi realizada uma revisão bibliográfica do ano de 2012 a 2017, nas bases de dados: LILACS e SCIELO, a partir dos descritores: Instituição de Longa Permanência para Idosos e Saúde Pública. Resultados: A amostra do presente estudo foi composta por 9 artigos. O maior número de produções no que tange as temáticas foi publicado no ano de 2015. Observou-se uma escassez de pesquisas sobre a assistência da saúde pública direcionada às ILPI’S. Conclusão: É necessário criar políticas públicas para as ILPI’S, que articulem suas ações na área da saúde pública e da assistência social.

Palavras-chave: Instituição de Longa Permanência para Idosos; Saúde Pública. 